\title{
Long-Term Socio-Ecological Research in Practice: Lessons from Inter- and Transdisciplinary Research in the Austrian Eisenwurzen
}

\author{
Simone Gingrich ${ }^{1}$ * , Martin Schmid ${ }^{1}$, Thomas Dirnböck ${ }^{2}$, Iwona Dullinger 1,3, \\ Rita Garstenauer ${ }^{4}$, Veronika Gaube ${ }^{1}$, Helmut Haberl ${ }^{1}$, Martin Kainz ${ }^{5}$, Daniel Kreiner ${ }^{6}$, \\ Renate Mayer ${ }^{7}$, Michael Mirtl ${ }^{2}$, Oliver Sass ${ }^{8}$, Thomas Schauppenlehner ${ }^{9}$, \\ Andrea Stocker-Kiss ${ }^{2}$ and Martin Wildenberg ${ }^{10}$
}

1 Institute of Social Ecology, Alpen-Adria Universitaet, 1070 Vienna, Austria; martin.schmid@aau.at (M.S.); iwona.dullinger@univie.ac.at (I.D.); veronika.gaube@aau.at (V.G.); helmut.haberl@aau.at (H.H.)

2 Department for Ecosystem Research and Environmental Information Management, Environment Agency Austria, 1090 Vienna, Austria; thomas.dirnboeck@umweltbundesamt.at (T.D.); michael.mirtl@umweltbundesamt.at (M.M.); andrea.stocker-kiss@umweltbundesamt.at (A.S.-K.) Vegetation Ecology and Landscape Ecology, Division of Conservation Biology, Department of Botany and Biodiversity Research, Vienna University, 1030 Vienna, Austria

6 Department of Nature Conservation/Research, Gesäuse National Park, 8911 Admont, Austria; daniel.kreiner@nationalpark.co.at

7 Agricultural Research and Education Center Raumberg-Gumpenstein, 8952 Irdning-Donnersbachtal, Austria; renate.mayer@raumberg-gumpenstein.at

8 Department of Geography and Regional Science, University of Graz, 8010 Graz, Austria; oliver.sass@uni-graz.at

9 Institute for Landscape Development, Recreation and Conservation Planning, University of Natural Resources and Life Sciences, 1180 Vienna, Austria; thomas.schauppenlehner@boku.ac.at

10 Research Centre of Expertise RCE-Vienna, Institute for Ecological Economics, Vienna University of Economics and Business, 1020 Vienna, Austria; martin.wildenberg@wu.ac.at

* Correspondence: simone.gingrich@aau.at; Tel.: +43-1-522-4000-418

Academic Editor: Marc A. Rosen

Received: 22 March 2016; Accepted: 26 July 2016; Published: 3 August 2016

\begin{abstract}
Long-Term Socio-Ecological Research (LTSER) is an inter- and transdisciplinary research field addressing socio-ecological change over time at various spatial and temporal scales. In the Austrian Eisenwurzen region, an LTSER platform was founded in 2004. It has fostered and documented research projects aiming at advancing LTSER scientifically and at providing regional stakeholders with relevant information for sustainable regional development. Since its establishment, a broad range of research activities has been pursued in the region, integrating information from long-term ecological monitoring sites with approaches from social sciences and the humanities, and in cooperation with regional stakeholders. Based on the experiences gained in the Eisenwurzen LTSER platform, this article presents current activities in the heterogeneous field of LTSER, identifying specific (inter-)disciplinary contributions of three research strands of LTSER: long-term ecological research, socio-ecological basic research, and transdisciplinary research. Given the broad array of diverse contributions to LTSER, we argue that the platform has become a relevant "boundary organization," linking research to its regional non-academic context, and ensuring interdisciplinary exchange among the variety of disciplines. We consider the diversity of LTSER approaches an important resource for future research. Major success criteria of LTSER face specific challenges: (1) existing loose, yet stable networks need to be maintained and extended; (2) continuous generation of and access to relevant data needs to be secured and more data need to be included; and
\end{abstract}


(3) consecutive research projects that have allowed for capacity building in the past may be threatened in the future if national Austrian research funders cease to provide resources.

Keywords: long-term socio-ecological research (LTSER); long-term ecological research (LTER); transdisciplinary cooperation; Eisenwurzen LTSER platform

\section{Introduction}

Long-term socio-ecological research (LTSER) is an inter- and transdisciplinary research agenda addressing socio-ecological change over time with the ultimate aim of providing meaningful knowledge for sustainable regional development, both to the scientific community and to stakeholders [1-3]. LTSER emerged out of long-term ecological research (LTER), which has a long tradition in ecosystem research. The significance of long-term change processes for understanding ecosystem functioning became apparent already in the early days of ecology. Appropriate infrastructures were established in the 19th (e.g., 1891-Plön, Germany; 1840-Rothamsted, England) and 20th centuries (e.g., 1906-Lunz, Austria; 1925-Trout Lake Station, Wisconsin, USA; 1955-Hubbard Brook, New Hampshire, USA; 1960-Solling, Germany). Since then it has been repeatedly shown that the study of long-term processes (spanning over several decades) has the potential to significantly improve system understanding [4-6]. LTER started to institutionalize in the United States in the 1980s [7-9] and established an international network ("ILTER") in 1993, involving 28 countries by the turn of the millennium [10].

Since the concept of sustainable development emerged in the 1980s (in particular after the publication of "Our common future" [11]), a consensus is emerging that scientific contributions to sustainable development need to include inter- and transdisciplinary approaches [12]. This insight motivated an extension of the LTER agenda to a broader approach that also considers societal processes driving environmental change, as well as feedbacks of environmental changes on society, and actively included regional stakeholders in research processes. LTSER was introduced as a new approach aiming to meet this challenge $[1,3,13]$. LTSER combines ecological research with social sciences and humanities and draws on integrating concepts like resilience [14], socioecological metabolism [15], and transdisciplinarity [16], with a particular emphasis on long-term trajectories. In total, 35 "LTSER platforms" have been established in Europe [17], institutionalizing and organizing LTSER in specific regional contexts (e.g., [18-20]). Similar efforts are being made outside Europe, e.g., in arid ecosystems in the Middle East [21], or in urban sites of North America [22].

The Austrian Eisenwurzen LTSER platform was among the first to be established, in 2004 [19]. LTSER carried out in this platform stands out internationally in terms of the degree of integration between natural sciences and the social sciences/humanities, as was pointed out by an international board of reviewers during the LTER-Austria conference in winter 2015. (General conclusions drawn from the reviews were presented at the conference. Reviewers included Stephan Glatzel, Geoecology, University of Vienna; Peter Groffman, Cary Institute of ecosystem studies; Hubbard Brook, Chair of US LTER Science Council and Executive Board; Elli Groner, Dead Sea and Arava Science Center; Terry Parr, CEH, UK; and Moshe Shachak, Chair Israel LTER, Ben Gurion University.) Starting from the observation that different disciplinary approaches pose different challenges to researchers, this article draws on the experience of researchers in the Eisenwurzen LTSER platform who convened in a workshop series in spring 2015 to discuss current research activities and to analyse success criteria and needs for further development.

Following a series of reports on the experiences of establishing LTSER platforms during their initial years of operation [17,18,22-24], this paper portrays a more "mature" LTSER platform in terms of the current state of inter- and transdisciplinary research. To this end, we analyse nine projects in 
terms of their disciplinary setup in three different strands of LTSER, identify current challenges, and derive success criteria for contemporary LTSER.

\section{The Eisenwurzen LTSER Platform: Regional Context, Methodological Approach, and Project Sample}

The Eisenwurzen region, situated at the edge of the Northern Austrian limestone Alps, is a heterogeneous landscape characterized by a common history of metal extraction and processing [25]. While the Eisenwurzen region itself is not exactly delineated [26], the LTSER platform has well-defined boundaries. It covers a total land area of $5904 \mathrm{~km}^{2}$ and 91 municipalities located in the three Austrian Federal Provinces Upper Austria, Lower Austria, and Styria (Figure 1). The Eisenwurzen LTSER platform covers a gradient of altitudes ranging from $167 \mathrm{~m}$ ASL to $2515 \mathrm{~m}$ ASL in the Southern Alpine part. The land area is dominated by forests (64\%) and managed grassland (13\%), as well as some intensive cropland areas in the Northern part of the region. It also includes many villages and several medium-sized towns [19]. The platform hosts 10 formal elements of research infrastructure where ecosystem patterns and processes are being studied (see Figure 1). In addition, several research institutions outside the region are involved in the LTSER platform by performing relevant research in the region.

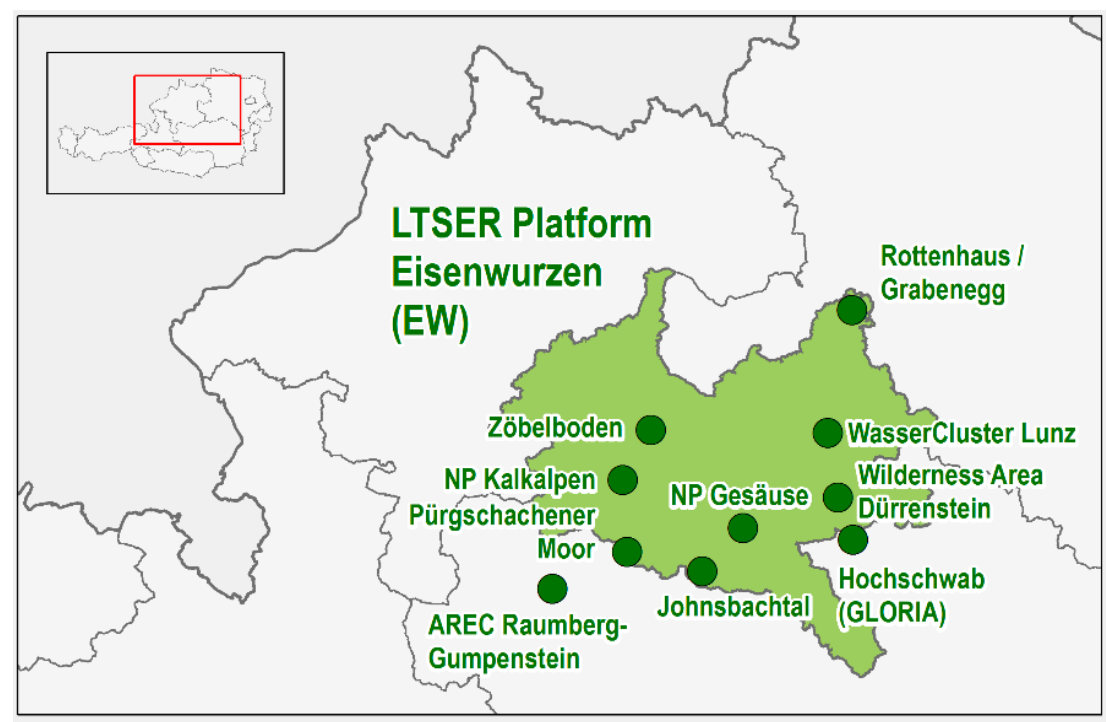

Figure 1. Location of the Austrian Eisenwurzen LTSER platform and its LTER sites.

Since 2004, the platform management has stimulated and integrated LTER and LTSER activities in the region, both between different research groups and between researchers and regional stakeholders. Regular workshops (c. one per year) involving researchers and stakeholders have been held to discuss and develop potentials for cooperation. The platform management has continuously collected information on LTSER projects from the researchers involved. Project data were fed into a database currently featuring more than 50 projects ranging from individual master's theses to large international cooperation projects. Figure 2 shows that the number of projects has risen significantly since the establishment of the platform. The share of internationally funded projects has decreased since 2004 because the EU's research integration funding (networks of excellence, Life+, INTERREG, etc.) was used to set up the platform at the beginning. In recent years, Austrian national funding schemes have played an increasingly important role for LTSER in the Eisenwurzen region. 


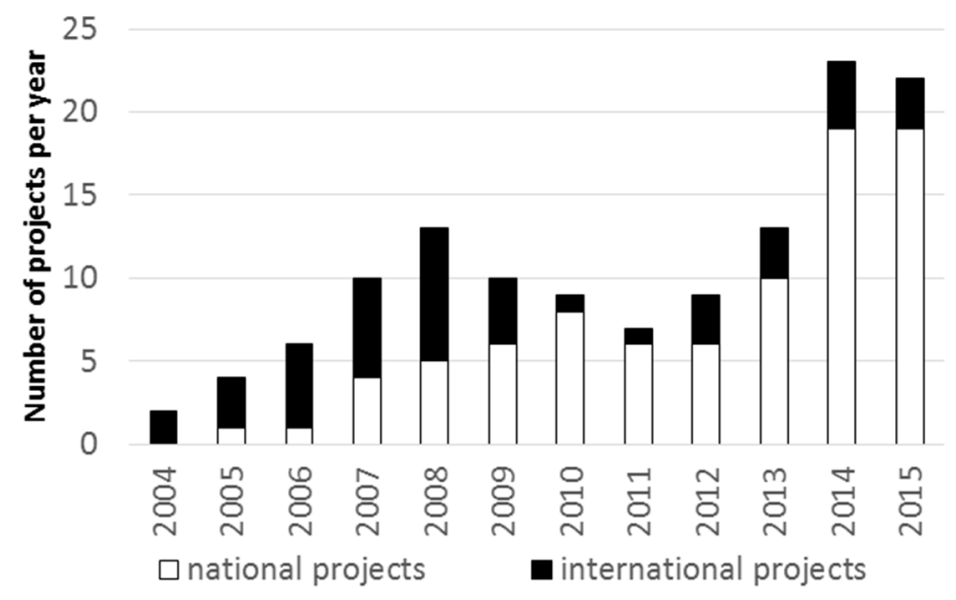

Figure 2. Number of ongoing projects in the Eisenwurzen LTSER platform each year since 2004. Projects with a duration of more than one calendar year are counted in each year of their duration. Source: Eisenwurzen LTSER platform management.

This study draws on the scientific networking activities of the platform performed in spring 2015. A series of two workshops was held in Vienna, gathering c. 15 researchers actively involved in LTSER projects in the region [27]. While previous events organized by the platform had involved both researchers and stakeholders, this workshop series was an attempt to foster exchange among researchers only, identify the current state of research, and define priorities for future activities.

In the first workshop a common understanding of currently ongoing LTSER activities in the region was established. Participants briefly presented their ongoing research projects. In the second workshop, three groups were formed to discuss challenges and success criteria of their respective approaches: (1) long-term ecological research; (2) socio-ecological basic research; and (3) transdisciplinary research. Success criteria of transdisciplinary cooperation were also discussed at a third workshop involving some researchers and several regional stakeholders [28]. Following these workshops, and based on the insights gained, a database on experiences of research and cooperation in the nine ongoing or recent LTSER projects (Table 1) was established. The sample of nine projects covers c. $16 \%$ of all research projects documented in the platform's database. The description of three strands of LTSER, with their challenges and success criteria, is based on individual project descriptions provided by the researchers involved. We first present the individual research strands in terms of their specific research topics, data, and methods used, and then discuss challenges and success criteria of LTSER developed across research strands. 
Table 1. Basic information on the projects discussed in this paper.

\begin{tabular}{|c|c|c|c|c|c|}
\hline Project & PI & Institution of PI & Funding Scheme & Duration of Project & Research Topic \\
\hline CentForCSink & Johannes Kobler & $\begin{array}{c}\text { Environment Agency } \\
\text { Austria }\end{array}$ & $\begin{array}{l}\text { National call for proposals of the Austrian } \\
\text { Climate Research Programme) }\end{array}$ & 2015-2018 & $\begin{array}{l}\text { Effects of past ecosystem disturbances on } \\
\text { later } C \text { sink in forests }\end{array}$ \\
\hline EXCARB & Tom Battin & WasserCluster Lunz & $\begin{array}{l}\text { National call for proposals of the Austrian } \\
\text { Academy of Sciences (Earth System Sciences) }\end{array}$ & 2014-2017 & $\begin{array}{l}\text { Possible effects of past and present } \\
\text { climate extremes on carbon fluxes; } \\
\text { Food web of lake Lunz }\end{array}$ \\
\hline Sedyn-X & Oliver Sass & University of Graz & Austrian Science Fund & 2013-2016 & $\begin{array}{l}\text { Sediment budget of the Johnsbach under } \\
\text { the viewpoints of renaturation, safety } \\
\text { and hydropower }\end{array}$ \\
\hline SFS & Geoff Cunfer & $\begin{array}{l}\text { University of Saskatchewan, } \\
\text { Canada }\end{array}$ & $\begin{array}{l}\text { Canadian Social Sciences and Humanities } \\
\text { Research Council }\end{array}$ & 2012-2016 & $\begin{array}{l}\text { Sustainability challenges in } \\
\text { agroecosystems in the course of } \\
\text { industrialization }\end{array}$ \\
\hline CC-ILA & Martin Schönhart & $\begin{array}{c}\text { University of Natural } \\
\text { Resources and Life Sciences, } \\
\text { Vienna }\end{array}$ & $\begin{array}{l}\text { National call for proposals of the Austrian } \\
\text { Academy of Sciences (Global Change } \\
\text { Programme) }\end{array}$ & 2010-2013 & $\begin{array}{l}\text { Climate change mitigation and } \\
\text { adaptation strategies for sustainable } \\
\text { rural land use developments }\end{array}$ \\
\hline Reich-raming & Helmut Haberl & Alpen-Adria University & $\begin{array}{l}\text { National research programme (Austrian } \\
\text { Federal Ministry of Education, Science and } \\
\text { Culture, ProVision Programme) }\end{array}$ & 2005-2009 & $\begin{array}{l}\text { Future land-use decisions taken by } \\
\text { regional stakeholders and their impact } \\
\text { on regional ecosystem } N \text { and } C \text { cycles }\end{array}$ \\
\hline LUBIO & Veronika Gaube & Alpen-Adria University & $\begin{array}{l}\text { National call for proposals of the Austrian } \\
\text { Academy of Sciences (Austrian Academy of } \\
\text { Sciences, Earth System Sciences) }\end{array}$ & 2015-2018 & $\begin{array}{l}\text { Direct and indirect land-use mediated } \\
\text { effects of a warming climate on plant } \\
\text { diversity }\end{array}$ \\
\hline Econnect & Christian Walzer & $\begin{array}{l}\text { University of Veterinary } \\
\text { Medicine, Vienna }\end{array}$ & EU Alpine Space Programme & 2008-2011 & $\begin{array}{l}\text { Enhancement of ecological connectivity } \\
\text { across the Alpine range and through } \\
\text { different actions in selected pilot regions }\end{array}$ \\
\hline BE-NATUR & Renate Mayer & $\begin{array}{l}\text { Agricultural Research and } \\
\text { Education Center } \\
\text { Raumberg-Gumpenstein }\end{array}$ & EU Interreg SEE & 2011-2014 & $\begin{array}{l}\text { Improving the transnational } \\
\text { management of Natura } 2000 \text { sites in } \\
\text { South-East European countries }\end{array}$ \\
\hline
\end{tabular}




\section{Three Research Strands of LTSER in the Eisenwurzen Region}

In the recently published LTER "White paper" [29], describing priority research themes, potentials, and framework conditions for LTER in Austria as a whole, LTER was divided into the thematic areas (1) "process-oriented ecosystem research"; (2) "biodiversity research and conservation biology"; and (3) "socio-ecological research, LTSER". For the purposes of this paper, we propose a slightly different categorization of LTSER, acknowledging the fact that LTSER aims at understanding change in ecosystems on the one hand and socio-ecological interactions on the other hand, and requires cooperation with stakeholders in order to produce meaningful knowledge for sustainable regional development. We identified the following three research strands characterized by particular methodological approaches and challenges:

(1) Long-term ecological research [30] investigating ecological patterns and processes. This strand applies mostly natural sciences methodologies to investigate ecological patterns and processes, using ecological evidence, e.g., from the platform's ecological monitoring sites.

(2) Socio-ecological basic research (e.g., [31]), focused on socio-economic drivers and responses to ecological change, as well as biophysical interactions between ecological and societal processes. In addition to ecological evidence, this strand requires information on socio-economic processes, and applies a variety of interdisciplinary methods informed by social sciences and humanities, as well as the natural sciences.

(3) Transdisciplinary research [32] in LTSER describes the interaction of researchers of any discipline with regional stakeholders, which is an activity that may be an element in research projects of either LTER or socio-ecological strands.

Given the interdisciplinary nature of LTSER, the research projects contribute to more than just one of the strands. Table 2 provides an overview of the individual contributions of projects to the strands.

Table 2. Contribution of the projects to different research strands of LTSER: ++ indicates major pillar of project; + important part of the project; minor part of the project; - no part of the project.

\begin{tabular}{cccc}
\hline Project & $\begin{array}{c}\text { Long-Term Ecological } \\
\text { Research }\end{array}$ & $\begin{array}{c}\text { Socio-Ecological Basic } \\
\text { Research }\end{array}$ & $\begin{array}{c}\text { Transdisciplinary } \\
\text { Cooperation }\end{array}$ \\
\hline CentForCSink & ++ & ++ & - \\
EXCARB & ++ & $\sim$ & $\sim$ \\
Sedyn-X & ++ & $\sim$ & - \\
SFS & - & ++ & + \\
CC-ILA & - & ++ & + \\
Reichraming & ++ & ++ & + \\
LUBIO & ++ & ++ & ++ \\
Econnect & ++ & + & ++ \\
BE-NATUR & ++ & + & + \\
\hline
\end{tabular}

\subsection{Long-Term Ecological Research}

Long-term ecological research is concerned with the long-term impacts of external and internal drivers on ecosystems. Ecosystem research is per se an interdisciplinary endeavour [33,34], involving contributions from abiotic and biotic research, and research at various spatio-temporal scales. In the Eisenwurzen LTSER platform, ecosystem monitoring sites provide rich databases for research. Many monitoring sites in the Eisenwurzen LTSER platform have been in existence for a long time, and are being used intensively in various research projects. Research benefits not only from a wealth of long-term data but also from a good system understanding generated by the researchers dealing with these data, supporting the development of new hypotheses. Monitoring and reporting (e.g., UNFCCC carbon emission reporting) also benefits from research findings because they allow 
for a more focused (e.g., which system variables are the most sensitive) and more cost-effective (e.g., sampling design) approach.

In the Eisenwurzen LTSER platform, ecosystems are analysed in terms of (1) biogeochemical ecosystem processes and matter fluxes, i.e., regulation of primary and secondary production in terrestrial and aquatic ecosystems, interactions between carbon, nutrient and water cycles, and their feedback effects on the climate, and ecosystem stability; and in terms of (2) biodiversity, in particular its links to ecosystem service provision and resource management [29].

In the sample of research projects, both issues are addressed. The projects CentForCSink, SEDYN-X, EXCARB, and Reichraming study ecosystem processes in terrestrial (forest, agricultural land) and aquatic (river and lake) ecosystems in the face of natural and societal drivers of change, such as natural disasters and climate change (CentForCSink, EXCARB), direct interventions in ecosystems like river training measures (SEDYN-X), or changes in subsidy systems, agricultural prices and other socio-economic variables (Reichraming). These projects share the common feature of using data from ecological monitoring sites (Zöbelboden, Johnsbachtal, Lake Lunz), which are available at a high spatio-temporal resolution. Connected to this data source is a joint challenge of working with big data from the monitoring sites, which has also been described at other LTER monitoring sites [35]. Two of the four projects addressing ecosystem processes integrate a substantial socio-ecological perspective: In CentForCSink, historians cooperate with ecologists to study long-term changes in forest management and their effects on forest carbon sinks [36,37]. In Reichraming, ecologists and interdisciplinary researchers from social ecology jointly studied the drivers of land use decision-making and their effects on land use-related substance flows [38]. Three of the four projects have little or no interaction with regional stakeholders. The only exception is the Reichraming project, which included a continuous participatory process with specific stakeholders, plus some educational outreach. Still, all projects make an effort to make their research results known to the regional public.

The research projects dealing with biodiversity research (Be-Natur, Econnect, LUBIO) study biodiversity of vegetation (LUBIO) or habitats in general (Be-Natur, Econnect). They investigate small-scale regions (LUBIO), regional (Econnect) and/or international (Be-Natur, Econnect) networks of protected areas. Biodiversity data in these projects are derived from samplings, from surveys carried out by administrative bodies, collected in stakeholder processes (see below), or available from previous research. Data challenges encountered in these projects referred to a variety of issues, namely access to data from different administrative bodies, data quality, and transferability across case studies. Biodiversity projects in the Eisenwurzen LTSER platform had very tight connections to regional stakeholders, which will be discussed below.

\subsection{Socio-Ecological Basic Research}

Socio-ecological basic research in LTSER investigates socio-economic processes driving and responding to ecological change, as well as the biophysical interactions between societies and ecosystems. Socio-ecological basic research expands the time periods under investigation in LTSER, using historical sources and developing future scenarios. The disciplines involved, accordingly, range from history (CentForCSink, SFS) to the planning sciences (CC-ILA). Projects mostly cover socio-economic processes directly affecting land use and management, i.e., agriculture (LUBIO, Reichraming, CC-ILA), forestry (CentForCSink), or both (SFS), or conservation management (Econnect, Be-Natur). In several projects, legal, economic, or technological aspects of land use change are analysed. Two projects (SEDYN-X and EXCARB) address socioeconomic processes only indirectly, focusing on the ecosystem effects of particular societal interventions rather than studying the interventions themselves. Socio-ecological basic research requires evidence on societal processes, which is derived from historical sources (CentForCSink, SFS) and aerial photographs (CC-ILA), official statistical surveys (SFS, LUBIO, Reichraming), and from stakeholder processes (Econnect, Be-Natur, CC-ILA, LUBIO, Reichraming).

Working with such data entails particular challenges, such as the integration of qualitative and quantitative information, the lack of compatibility of data sources describing different time periods, 
or data availability at different scales. Generally, time periods from the more distant past tend to be characterized by scarcer data availability (although individual sources may provide overwhelmingly detailed information). Transforming evidence from historical sources into quantitative socioecological indicators requires rigid methodical control [39].

There are different degrees of integration between socioeconomic and ecological research in the Eisenwurzen LTSER platform, which can be placed along the gradient from "multi-" to "interdisciplinarity" [40]. The most common strategy uses medium-range interdisciplinary approaches, integrating research questions beyond disciplines. Interdisciplinary approaches such as environmental history (SFS), social ecology (LUBIO, Reichraming), or agronomy (CC-ILA) are adopted successfully and continuously in the Eisenwurzen LTSER platform. Interdisciplinary projects investigate processes in ecosystems and society at a uniform spatio-temporal scale, addressing issues such as pre-industrial sustainability problems of land use and land management [41], the causes of farmers' decision-making and their effects on landscape and ecosystem features [38], or potential sustainable climate change mitigation and adaptation strategies in extensive farming [42]. The strength of these approaches is their capability to analyse causal relations between heterogeneous types of drivers and impacts, risks, vulnerabilities, and resilience.

Another strategy to integrate socioeconomic and ecological research is multidisciplinary cooperation, which is applied in the recently started project CentForCSink. In this project, research is carried out by different disciplines individually at the respective scales of data availability [43]. Results are juxtaposed and combined in ecological models. Integration of findings takes place mostly after disciplinary data evaluation and analysis. This strategy brings forward pioneering approaches to temporal and spatial upscaling and allows for cross-fertilization of previously disconnected research approaches.

\subsection{Transdisciplinary Research}

LTSER aims to be context-driven and problem-focused and intends to foster regionally integrated research contributing to sustainable regional development. This strand of LTSER is part of the broad field of transdisciplinary sustainability sciences $[44,45]$. Out of nine projects in our sample, only two do not interact with regional stakeholders at all, while two involve regional stakeholders only as recipients of relevant project results, e.g., through media reports in regional media, leaflets produced with the national park, or in single interactions e.g., in individual interviews.

The other five projects (CC-ILA, LUBIO, Reichraming, Econnect, and Be-Natur) vary strongly in terms of which and how many stakeholders they involve, but less so in terms of how collaboration between researchers and stakeholders operates in the three crucial phases: co-design, co-production, and integration in non-scientific practice [44].

CC-ILA, LUBIO, and Reichraming were funded by Austrian national grants for inter- and transdisciplinary research projects, and conducted by Austrian University Institutes that involved regional partners. At the core of the three projects were scientific research questions on land-use related decision-making and its effects on landscapes [46], which had partly been developed with or proposed to regional stakeholders. These three projects involved small groups of stakeholders only (regional farmers, agricultural experts, some political decision-makers), who provided context-specific knowledge and were interested in project outcomes. In all three projects, modelling and scenario development were used as methods to achieve results relevant for academia, as well as for local stakeholders, which were informed on the potential long-term effects of their decision-making.

Econnect and Be-Natur were funded by EU regional development funds (INTERREG and the Alpine Space Programme), thus their focus was less on basic research and more on implementation of results. Both projects collaborated with regional stakeholders to improve nature conservation measures in the region and beyond [47,48]. The institutions involved in the Eisenwurzen LTSER platform are regional, non-academic research institutions with close links to regional non-scientific stakeholders. Both projects collaborated with a wide variety and a high number of stakeholders, 
including land users, nature conservation managers, representatives from regional development, and teachers, among others.

Table 3 displays the elements of knowledge co-design, co-production, and integration to societal processes in the five projects. Knowledge co-production was realized using similar methods in all projects (though a slightly broader variety was used in Econnect and Be-Natur). The projects differ more strongly in terms of implementation and application of project results.

Table 3. Cooperation of researchers and stakeholders in different project stages of transdisciplinary LTSER projects in the Eisenwurzen.

\begin{tabular}{|c|c|c|c|c|c|}
\hline Project & CC-ILA & LUBIO & Reichraming & Econnect & Be-Natur \\
\hline \multicolumn{6}{|c|}{ Co-Design } \\
\hline Joint project development with selected stakeholders & & & + & + & + \\
\hline Workshop in region prior to project start & + & & & + & \\
\hline \multicolumn{6}{|c|}{ Co-production of knowledge } \\
\hline Workshops & + & + & + & + & + \\
\hline Interviews & & + & + & + & \\
\hline Focus groups & & & + & + & \\
\hline Excursions & & & & + & + \\
\hline Data collection/monitoring & + & & + & + & + \\
\hline \multicolumn{6}{|c|}{ Implementation and application of created knowledge } \\
\hline Final conference/workshop & + & + & + & + & + \\
\hline Action plans/policy recommendations & + & & & + & + \\
\hline Training/education & & & + & + & + \\
\hline Printed material & & & & + & + \\
\hline
\end{tabular}

The benefits of transdisciplinary collaboration were "normative" and "substantive" [49] in all projects, i.e., regional stakeholder involvement encouraged social and individual learning, and improved the understanding of the research questions addressed. Transdisciplinary cooperation was also "instrumental" in Econnect and Be-Natur, where stakeholder processes facilitated implementation of project outcomes.

\section{Discussion: Structural Success Criteria}

The presentation of the different strands in the Eisenwurzen LTSER platform has shown that LTSER is a very heterogeneous inter- and transdisciplinary endeavour. It goes far beyond Long-term ecological research (LTER), from which it emerged. The heterogeneity of approaches and institutions is a typical challenge during the implementation stage of LTSER platforms [18,24]. In the Eisenwurzen LTSER platform, this diversity has not decreased in the course of over 10 years of inter- and transdisciplinary cooperation, as outlined above. Instead, the variety and breadth of approaches to LTSER have remained a source of innovation. The prosperousness of each of the strands described in this paper appears to be as important for future LTSER as their continuing exchange. We now discuss three major success criteria we believe to be crucial for LTSER to thrive and address their relevance to the three research strands discussed and their potential future challenges.

\subsection{A Loose, yet Stable Network}

The first success criterion draws on the above-described observation that diversity of research approaches remains an important feature of the Eisenwurzen LTSER platform. This diversity of approaches allows for tapping various funding sources and thus contributes to reducing excess competition for funding. It is, in combination with the loose yet stable network offered by the LTSER platform, also a continuous source of innovation. The stability of the LTSER network is granted by c. one meeting per year organized by the platform management to assure steady exchange of information and scrutinizing scientific and socio-environmental development. 
All projects discussed in this contribution involve more than one institution, and all collaborations had been established more or less informally before the work on the respective project proposal. Many collaborations benefitted from the activities of the LTSER platform management. A solid network is particularly important in transdisciplinary cooperation, where the LTSER platform acts as a "boundary organization" [50], fostering the flow of information between science and regional stakeholders. But also the continuous interaction of researchers from different disciplines, e.g., ecologists working with data from LTER-monitoring sites together with environmental historians has led to interdisciplinary projects like CentForCSink that otherwise may not have been realized.

In general, the networking activities of the LTSER platform may be considered quite successful, given the large amount of inter- and transdisciplinary activities involving a wide variety of actors. In order to avoid the trap of choosing "usual suspects" as project partners, rather than actually suitable partners [44], existing networks should be extended by including research disciplines that have not been involved for contingent reasons but could contribute relevant insights, such as prehistory, (historical) archaeology or the archaeo-sciences. For transdisciplinary collaboration, each new project faces the challenge of harmonising potentially diverging expectations of researchers and stakeholders. Realistic compromises between the hopes of stakeholders and doable scientific contributions [51] need to be established in each project. This is particularly important in the heavily researched Eisenwurzen region: disappointment caused by unsuccessful cooperation in one project may have medium-term effects hampering future collaboration in successive projects. In discussions among researchers, as well as between researchers and stakeholders, several success criteria for collaboration were identified that refer to the individuals involved and build the basis for establishing trust in collaborations [52]. These include open-mindedness and a positive, respectful attitude towards the different perspectives and methodological approaches of cooperation partners.

\subsection{Availability of and Access to Data and Information}

Across research strands, availability of and access to data and information was identified as the second major reason why the Eisenwurzen LTSER platform has been able to successfully attract research activities. Availability of and access to data varies greatly among the three research strands discussed in this paper, resulting from the different types of "data" that each strand works with. In ecological research using monitoring sites, data tend to be overly abundant, and problems are mostly related to managing long-term data [35] and upscaling the data to scales for which other sources, e.g., historical records, are available. Professional management of the large data supplied in the LTER monitoring sites is a major prerequisite in this task. In biodiversity research, data availability is more scattered, with different relevant data holders (e.g., provincial conservation authorities) holding data sources. In addition to data compatibility, access to data is a major issue here.

In socio-ecological basic research, data sources are very diverse, and tend to be scarce and scattered. In the projects considered, the identification or generation of suitable source material is a specific bottleneck for good research. In socio-ecological basic research, many of the socio-economic data produced and/or used in individual projects are not publicly available beyond what is published in articles or books. In order to foster more socio-ecological basic research in the region, the Eisenwurzen LTSER platform is renewing efforts in compiling information on potential archives, publications, or databases providing relevant socio-economic data.

For transdisciplinary research, the most important information requirement is who to collaborate with. As noted above, the platform has successfully adopted a role as a "boundary organization" [50] facilitating exchange between researchers and stakeholders. This role works particularly well when researchers seek contact with regional stakeholders. While identifying the right stakeholders is usually successful, several projects find involving enough stakeholders (e.g., several farmers of one village) a challenge. In addition, the translation of regional needs and interests into research questions that may be addressed in projects has been less productive in the past and remains to be developed further, 
making use of recent research on improving dialogue between researchers and decision-makers (e.g., [53]).

\subsection{Continuous Funding}

Attracting continuous funding to LTSER in the region is a major challenge reported in all research strands. The LTSER platform has contributed to address this challenge by establishing networks and providing infrastructure (monitoring sites, metadatabases, contacts to various researchers and stakeholders), two factors facilitating projects in the region. As in other countries, several Austrian calls for research projects in the field of environmental and sustainability research explicitly require the collaboration of researchers with stakeholders [54], as well as the use of existing research infrastructure. Both of these requirements have contributed to researchers' decisions for the Eisenwurzen as case study region. Several series of successive projects have helped overcome one of the most important challenges of many transdisciplinary processes, which is that they end after project funding stops [55]. The continued attraction of research to the region and to specific actors has additionally allowed for building up (transdisciplinary) research capacity. The development of socio-ecological modelling, a particularly useful approach to inter- and transdisciplinary research [56], in the projects Reichraming and LUBIO, but also in CC-ILA and CentForCSink is an example for interdisciplinary capacity building in the Eisenwurzen LTSER platform.

A potential future risk outside the scope of the LTSER platform appears to be the funding situation of LTSER projects in Austria. As we showed in the introduction, the number of LTSER projects in the Eisenwurzen has been growing, in particular based on national funding, and here national funding schemes have played a crucial role. This may be explained by the lack of funding opportunities for transdisciplinary research in the Austrian National Science Fund, which handles most of the competitive basic research funding in Austria. While international funding (EU and other) does contribute significantly to LTSER in the Eisenwurzen, the future of LTSER will also depend on national funding schemes specifically targeting the integration of excellent research with regional stakeholders. Bringing in international researchers through the European transnational access programs to research infrastructure (e.g., EU Horizon project eLTER) will be important in the future.

Acknowledgments: The process leading to this paper was funded by the Austrian Society for Long-term Ecological Research through the Austrian Academy of Sciences. We thank Christoph Wohner for providing the map presented in Figure 1. We thank two anonymous reviewers for their valuable comments which greatly improved the manuscript.

Author Contributions: All co-authors contributed to designing the paper during and following a workshop series in spring 2015. Simone Gingrich and Martin Schmid wrote most of Sections 1-4. Thomas Dirnböck, Helmut Haberl, Veronika Gaube, Andrea Stocker-Kiss, and Michael Mirtl contributed to writing these sections.

Conflicts of Interest: The authors declare no conflict of interest.

\section{References}

1. Haberl, H.; Winiwarter, V.; Andersson, K.; Ayres, R.U.; Boone, C.; Castillo, A.; Cunfer, G.; Fischer-Kowalski, M.; Freudenburg, W.R.; Furman, E.; et al. From LTER to LTSER: Conceptualizing the Socioeconomic Dimension of Long-term Socioecological Research. Ecol. Soc. 2006, 11, 13.

2. Ohl, C.; Johst, K.; Meyerhoff, J.; Beckenkamp, M.; Grüsgen, V.; Drechsler, M. Long-term socio-ecological research (LTSER) for biodiversity protection-A complex systems approach for the study of dynamic human-nature interactions. Ecol. Complex. 2009. [CrossRef]

3. Redman, C.L.; Grove, J.M.; Kuby, L.H. Integrating Social Science into the Long-Term Ecological Research (LTER) Network: Social Dimensions of Ecological Change and Ecological Dimensions of Social Change. Ecosystems 2004, 7, 161-171. [CrossRef]

4. Hobbie, J.E.; Carpenter, S.R.; Grimm, N.B.; Gosz, J.R.; Seastedt, T.R. The US Long Term Ecological Research Program. BioScience 2003, 53, 21-32. [CrossRef]

5. Lindenmayer, D.B.; Likens, G.E. Adaptive monitoring: A new paradigm for long-term research and monitoring. Trends Ecol. Evol. 2009, 24, 482-486. [CrossRef] [PubMed] 
6. Magnuson, J.J. Long-Term Ecological Research and the Invisible Present. BioScience 1990, 40, 495-501. [CrossRef]

7. Callahan, J.T. Long-Term Ecological Research. BioScience 1984, 34, 363-367. [CrossRef]

8. Franklin, J.F.; Bledsoe, C.S.; Callahan, J.T. Contributions of the Long-Term Ecological Research Program. BioScience 1990, 40, 509-523. [CrossRef]

9. Gosz, J.; Waide, R.; Magnuson, J. Twenty-Eight Years of the US-LTER Program: Experience, Results, and Research Questions. In Long-Term Ecological Research; Müller, F., Baessler, C., Schubert, H., Klotz, S., Eds.; Springer: Dordrecht, The Netherland, 2010; pp. 59-74.

10. Mirtl, M. Introducing the Next Generation of Ecosystem Research in Europe: LTER-Europe's Multi-Functional and Multi-Scale Approach. In Long-Term Ecological Research; Müller, F., Baessler, C., Schubert, H., Klotz, S., Eds.; Springer: Dordrecht, The Netherland, 2010; pp. 75-93.

11. Brundtland, G.H. Our Common Future; Oxford University Press: Oxford, UK, 1987.

12. Kates, R.W.; Clark, W.C.; Corell, R.; Hall, J.M.; Jaeger, C.C.; Lowe, I.; McCarthy, J.J.; Schellnhuber, H.J.; Bolin, B.; Dickson, N.M.; et al. Environment and Development: Sustainability Science. Science 2001, 292, 641-642. [CrossRef] [PubMed]

13. Collins, S.L.; Carpenter, S.R.; Swinton, S.M.; Orenstein, D.E.; Childers, D.L.; Gragson, T.L.; Grimm, N.B.; Grove, J.M.; Harlan, S.L.; Kaye, J.P.; et al. An integrated conceptual framework for long-term social-ecological research. Front. Ecol. Environ. 2011, 9, 351-357. [CrossRef]

14. Holling, C.S. The resilience of terrestrial ecosystems: Local surprise and global change. In Sustainable Development of the Biosphere; Clark, W.C., Munn, R.E., Eds.; Cambridge University Press: Cambridge, UK, 1986; pp. 292-320.

15. Gonzalez de Molina, M.; Toledo, V.M. The Social Metabolism. A Socio-Ecological Theory of Historical Change; Environmental History; Springer: New York, NY, USA, 2014; Volume 3.

16. Hirsch Hadorn, G.; Bradley, D.; Pohl, C.; Rist, S.; Wiesmann, U. Implications of transdisciplinarity for sustainability research. Ecol. Econ. 2006, 60, 119-128. [CrossRef]

17. Mirtl, M.; Orenstein, D.; Wildenberg, M.; Peterseil, J.; Frenzel, M. Development of LTSER Platforms in LTER-Europe: Challenges and Experiences in Implementing Place-Based Long-Term Socio-ecological Research in Selected Regions. In Long Term Socio-Ecological Research; Singh, S.J., Haberl, H., Chertow, M., Mirtl, M., Schmid, M., Eds.; Human-Environment Interactions; Springer: Dordrecht, The Netherlands, 2013; Volume 2, pp. 409-442.

18. Furman, E.; Peltola, T. Developing Socio-ecological Research in Finland: Challenges and Progress towards a Thriving LTSER Network. In Long Term Socio-Ecological Research. Studies in Society-Nature Interactions across Spatial and Temporal Scales; Singh, S.J., Haberl, H., Chertow, M., Mirtl, M., Schmid, M., Eds.; Human-Environment Interactions; Springer: Berlin, Germany; Heidelberg, Germany, 2013; Volume 2.

19. Peterseil, J.; Neuner, A.; Stocker-Kiss, A.; Gaube, V.; Mirtl, M. The Eisenwurzen LTSER Platform (Austria)-Implementation and Services. In Long Term Socio-Ecological Research. Studies in Society-Nature Interactions across Spatial and Temporal Scales; Springer Science + Business Media B.V.: Dordrecht, The Netherlands, 2013; Volume 2, pp. 461-484.

20. Mauz, I.; Peltola, T.; Granjou, C.; van Bommel, S.; Buijs, A. How scientific visions matter: Insights from three long-term socio-ecological research (LTSER) platforms under construction in Europe. Environ. Sci. Policy 2012, 19-20, 90-99. [CrossRef]

21. Orenstein, D.E.; Groner, E. Using the Ecosystem Services Framework in a Long-Term Socio-Ecological Research (LTSER) Platform: Lessons from the Wadi Araba Desert, Israel and Jordan. In Earth Stewardship; Rozzi, R., Chapin, F.S., III, Callicott, J.B., Pickett, S.T.A., Power, M.E., Armesto, J.J., May, R.H., Eds.; Springer International Publishing: Cham, Switzerland, 2015; Volume 2, pp. 281-296.

22. Grove, J.M.; Pickett, S.T.A.; Whitmer, A.; Cadenasso, M.L. Building an Urban LTSER: The Case of the Baltimore Ecosystem Study and the D.C./B.C. ULTRA-Ex Project. In Long Term Socio-Ecological Research; Singh, S.J., Haberl, H., Chertow, M., Mirtl, M., Schmid, M., Eds.; Springer: Dordrecht, The Netherlands, 2013; pp. 369-408.

23. Lavorel, S.; Spiegelberger, T.; Mauz, I.; Bigot, S.; Granjou, C.; Dobremez, L.; Nettier, B.; Thuiller, W.; Brun, J.-J.; Cozic, P. Fostering Research into Coupled Long-Term Dynamics of Climate, Land Use, Ecosystems and Ecosystem Services in the Central French Alps. In Long Term Socio-Ecological Research; Singh, S.J., Haberl, H., Chertow, M., Mirtl, M., Schmid, M., Eds.; Springer: Dordrecht, The Netherlands, 2013; pp. 485-504. 
24. Tappeiner, U.; Borsdorf, A.; Bahn, M. Long-Term Socio-ecological Research in Mountain Regions: Perspectives from the Tyrolean Alps. In Long Term Socio-Ecological Research; Singh, S.J., Haberl, H., Chertow, M., Mirtl, M., Schmid, M., Eds.; Springer: Dordrecht, The Netherlands, 2013; pp. 505-525.

25. Schuh, G.; Sieghartsleitner, F. Heimat Eisenwurzen. Beiträge zum Eisenstraßensymposium Weyer; Ennstaler Verlag: Steyr, Austria, 1997. (In German)

26. Heintel, M.; Weixlbaumer, N. Region Eisenwurzen: Ein geographisch-kulturräumlicher Begriff. In Land der Hämmer-Heimat Eisenwurzen; Residenz-Verlag: Salzburg, Austria, 1998. (In German)

27. Workshop Documentation “Konzeption und Inhaltliche Schwerpunktsetzung”. Available online: http: //www.umweltbundesamt.at/umweltsituation/lter_allgemein/lter_aktivitaeten/wien_2015/ (accessed on 28 July 2016). (In German)

28. Documentation “Workshop der LTSER Plattform Eisenwurzen 2015". Available online: http://www. umweltbundesamt.at/umweltsituation/lter_allgemein/lter_aktivitaeten/irdning2015 (accessed on 28 July 2016). (In German)

29. Mirtl, M.; Bahn, M.; Battin, T.; Borsdorf, A.; Dirnböck, T.; Englisch, M.; Erschbamer, B.; Fuchsberger, J.; Gaube, V.; Grabherr, G.; et al. Research for the Future-LTER-Austria White Paper 2015 on the Status and Orientation of Process Oriented Ecosystem Research, Biodiversity and Conservation Research and Socio-Ecological Research in Austria. Available online: https://www.uibk.ac.at/geographie/personal/ borsdorf/pdfs/lter_austria_white_paper_2015_engl_printversion.pdf (accessed on 28 July 2016).

30. Müller, F.; Baessler, C.; Klotz, S.; Schubert, H. Long-Term Ecological Research: Between Theory and Application; Springer: Berlin, Germany, 2010.

31. Social Ecology. In Society-Nature Relations across Time and Space; Haberl, H., Fischer-Kowalski, M., Krausmann, F., Winiwarter, V., Eds.; Springer: Berlin, Germany; Heidelberg, Germany; New York, NY, USA, 2016.

32. Hirsch Hadorn, G., Hoffmann-Riem, G., Biber-Klemm, S., Grossenbacher-Mansuy, W., Joye, D., Pohl, C., Wiesmann, U., Zemp, E. (Eds.) Handbook of Transdisciplinary Research; Springer: New York, NY, USA, 2008.

33. Pickett, S.T.A. Interdisciplinary Research: Maintaining the Constructive Impulse in a Culture of Criticism. Ecosystems 1999, 2, 302-307. [CrossRef]

34. Gershon, D. Pushing the frontiers of interdisciplinary research: An idea whose time has come. Nature 2000, 404, 313-315. [CrossRef] [PubMed]

35. Karasti, H.; Baker, K.S.; Halkola, E. Enriching the Notion of Data Curation in E-Science: Data Managing and Information Infrastructuring in the Long Term Ecological Research (LTER) Network. Comput. Support. Cooper. Work 2006, 15, 321-358. [CrossRef]

36. Erb, K.-H.; Kastner, T.; Luyssaert, S.; Houghton, R.A.; Kuemmerle, T.; Olofsson, P.; Haberl, H. Bias in the attribution of forest carbon sinks. Nat. Clim. Chang. 2013, 3, 854-856. [CrossRef]

37. Gingrich, S.; Erb, K.-H.; Krausmann, F.; Gaube, V.; Haberl, H. Long-term dynamics of terrestrial carbon stocks in Austria: A comprehensive assessment of the time period from 1830 to 2000. Reg. Environ. Chang. 2007, 7, 37-47. [CrossRef]

38. Gaube, V.; Kaiser, C.; Wildenberg, M.; Adensam, H.; Fleissner, P.; Kobler, J.; Lutz, J.; Schaumberger, A.; Schaumberger, J.; Smetschka, B.; et al. Combining agent-based and stock-flow modelling approaches in a participative analysis of the integrated land system in Reichraming, Austria. Landsc. Ecol. 2009, 24, 1149-1165. [CrossRef]

39. Bauer, M. Agrarsysteme in Niederösterreich im Frühen 19. Jahrhundert. Eine Analyse auf Basis der Schätzungsoperate des Franziszeischen Katasters. Available online: http://www.ruralhistory.at/de/ publikationen/rhwp/RHWP20.pdf (accessed on 28 July 2016). (In German)

40. Thompson Klein, J. A taxonomy of interdisciplinarity. In The Oxford Handbook of Interdisciplinarity; Frodeman, R., Ed.; Oxford University Press: New York, NY, USA, 2010.

41. Gingrich, S.; Haidvogl, G.; Krausmann, F.; Preis, S.; Garcia-Ruiz, R. Providing Food while Sustaining Soil Fertility in Two Pre-industrial Alpine Agroecosystems. Hum. Ecol. 2015, 43, 395-410. [CrossRef]

42. Schönhart, M.; Schauppenlehner, T.; Schmid, E.; Muhar, A. Analysing the maintenance and establishment of orchard meadows at farm and landscape levels applying a spatially explicit integrated modelling approach. J. Environ. Plan. Manag. 2011, 54, 115-143. [CrossRef]

43. Szabó, P.; Hédl, R. Advancing the Integration of History and Ecology for Conservation: History, Ecology, and Conservation. Conserv. Biol. 2011, 25, 680-687. [CrossRef] [PubMed] 
44. Lang, D.J.; Wiek, A.; Bergmann, M.; Stauffacher, M.; Martens, P.; Moll, P.; Swilling, M.; Thomas, C.J. Transdisciplinary research in sustainability science: Practice, principles, and challenges. Sustain. Sci. 2012, 7, 25-43. [CrossRef]

45. Brandt, P.; Ernst, A.; Gralla, F.; Luederitz, C.; Lang, D.J.; Newig, J.; Reinert, F.; Abson, D.J.; von Wehrden, H. A review of transdisciplinary research in sustainability science. Ecol. Econ. 2013, 92, 1-15. [CrossRef]

46. Found, W.C. A Theoretical Approach to Rural Land-Use Patterns; Arnold: London, UK, 1974.

47. Reyers, B.; Roux, D.J.; Cowling, R.M.; Ginsburg, A.E.; Nel, J.L.; Farrell, P.O. Conservation Planning as a Transdisciplinary Process: Putting Conservation Plans to Work. Conserv. Biol. 2010, 24, 957-965. [CrossRef]

48. Neßhöver, C.; Timaeus, J.; Wittmer, H.; Krieg, A.; Geamana, N.; van den Hove, S.; Young, J.; Watt, A. Improving the science-policy interface of biodiversity research projects. GAIA Ecol. Perspect. Sci. Soc. 2013, 22, 99-103.

49. Blackstock, K.L.; Kelly, G.J.; Horsey, B.L. Developing and applying a framework to evaluate participatory research for sustainability. Ecol. Econ. 2007, 60, 726-742. [CrossRef]

50. Pohl, C. From science to policy through transdisciplinary research. Environ. Sci. Policy 2008, 11, 46-53. [CrossRef]

51. Haas, W.; Singh, S.J.; Erschbamer, B.; Reiter, K.; Walz, A.; Singh, S.J. Integrated Monitoring and Sustainability Assessment in the Tyrolean Alps: Experiences in Transdisciplinarity. In Long Term Socio-Ecological Research. Studies in Society-Nature Interactions across Spatial and Temporal Scales; Springer Science + Business Media B.V.: Dordrecht, The Netherlands, 2013; Volume 2, pp. 527-554.

52. Harris, F.; Lyon, F. Transdisciplinary environmental research: Building trust across professional cultures. Environ. Sci. Policy 2013, 31, 109-119. [CrossRef]

53. Nesshöver, C.; Vandewalle, M.; Wittmer, H.; Balian, E.V.; Carmen, E.; Geijzendorffer, I.R.; Görg, C.; Jongman, R.; Livoreil, B.; Santamaria, L.; et al. The Network of Knowledge approach: Improving the science and society dialogue on biodiversity and ecosystem services in Europe. Biodivers. Conserv. 2016, 25, 1215-1233. [CrossRef]

54. Van Kerkhoff, L. Integrated research: Concepts of connection in environmental science and policy. Environ. Sci. Policy 2005, 8, 452-463. [CrossRef]

55. Pooley, S.P.; Mendelsohn, J.A.; Milner-Gulland, E.J. Hunting down the Chimera of Multiple Disciplinarity in Conservation Science: Multiple Disciplinarity in Conservation. Conserv. Biol. 2014, 28, 22-32. [CrossRef] [PubMed]

56. Heemskerk, M.; Wilson, K.; Pavao-Zuckerman, M. Conceptual models as tools for communication across disciplines. Conserv. Ecol. 2003, 7, 8 . 